\title{
COVID-19 Response for the Hundred Years
}

\author{
Hee Ja Na \\ Department of Dental Hygiene, Honam University, Gwangju, Korea
}

Patients who visit the dentist for treatment these days are very nervous and will be worried about exposure to coronavirus. However, the spread of coronavirus in dentistry has not been reported as oral disinfection is thoroughly performed prior to treatment and treatment begins. In order to prevent the COVID-19 infectious disease, dental workers should check whether there are no symptoms of COVID-19 such as fever, coughing, sore throat, and muscle pain before dental treatment and check whether they are vulnerable to infection such as base disease or pregnant women.

Keywords: COVID-19 infectious disease, dental workers, fever, coughing, sore throat, muscle pain

\section{Introduction}

According to the prevention and management of COVID19 infection at dental institutions, employees should be trained on coronavirus infection prevention rules, hand hygiene and removal of protective gear. It also conducts staff monitoring of COVID-19 infections and implements appropriate measures [1]. Patient reception and management will then minimize waiting time by implementing an outpatient pre-order system and check risk factors such as COVID-19 symptoms and contact of patients when booking and receiving medical treatment. The management of the entrance and waiting room shall attach promotional materials, such as notices for the prevention of COVID-19, at the entrance [2]. If you have fever or respiratory symptoms, you are advised to receive selective medical treatment, and visitors are advised to wear hand hygiene, mask, check fever, and access records, and minimize waiting patients [3]. Patient management selects

\section{Corresponding author Hee Ja Na}

E-mail: artnahee@naver.com

(iD) https://orcid.org/0000-0002-8234-2957

Received June 24, 2021, Accepted June 28, 2021 and wears appropriate personal protective equipment according to the type of procedure before the procedure begins, and sterilizes the surface that the patient has contacted after each patient's treatment. Then, after the aerosol-producing procedure, disinfect and ventilate them after finishing [4]. In the case of equipment and environmental management, equipment used shall be disposed of or disinfected in a container to prevent contamination of the surroundings [5]. Environmental surfaces with frequent contact should be frequently cleaned with disinfectants, cleaned and disinfected before properly ventilating [5]. The mask, gown, personal, face protection, personal protection equipment and office and Shoulder disinfecting the waiting room. During dental treatment, masks, goggles, and facial protectors must be worn to prevent the patient's blood or fluid from splashing to the dentist's eyes, nose and mouth mucous membrane, and the mask (n95) must be replaced for each patient [6]. Proper adherence to infection control principles to block the spread of COVID19 in dental clinics is crucial to protect patients and medical staff.

Copyright (C) 2021. Korean Academy of Preventive Dentistry. All rights reserved.

This is an Open Access article distributed under the terms of the Creative Commons Attribution Non-Commercial License (http://creativecommons.org/licenses/ by-nc/4.0) which permits unrestricted non-commercial use, distribution, and reproduction in any medium, provided the original work is properly cited. 


\section{Discussion}

The most notorious pandemic in history is the Black Death, which claimed the lives of a third of Europe's population in the Middle Ages. Following the 1918 Spanish flu, 1957 Asian flu, 1968 Hong Kong flu, and 2009 swine flu, the World Health Organization (WHO) declared a pandemic against COVID19. Above all, it is important to find the infected person through a quick diagnosis and prevent the spread of infectious diseases early on. Corona pandemic is accelerating the integration of digital technologies in various fields, including education, economy, culture, politics and sports. In response, he expresses his opinion by shortening the leadership requirements while devising a column on the leader award that will wisely lead the future in the existing digital civilization society where confusing human conflicts and divisions exist. The future leader needs a spirit of patriotism and must realize a centenary against the pandemic.

\section{Conclusion}

Given the WHO's declaration of a pandemic against COVID-19, it is natural to speculate on what viruses will emerge again in the future. Therefore, Korean or world leaders are expected to join forces with science and technology and health care to establish a healthcare centenary to prepare for future strains of the virus or treatments. Currently, coronavirus injections are being vaccinated first for the elderly and health care workers, but businessmen and international students who must leave the country to protect their citizens should strengthen their systems to get vaccinated before departure.

Recently, thoroughly protecting personal hygiene management has become protecting one's life. In particular, we thank and encourage dental workers who are responsible for the safety and hygiene of patients and are engaged in treatment by fighting the virus on the front line of dental clinicians.

\section{Conflict of Interest}

No potential conflict of interest relevant to this article was reported.

\section{ORCID}

Hee Ja Na, https://orcid.org/0000-0002-8234-2957

\section{References}

1. Novel coronavirus (2019-nCoV) infection prevention and control guidance Updated 3 February 2020.

2. Novel coronavirus (2019-nCoV) infection prevention and control guidance (2020.2.3.)

3. Novel coronavirus (2019-nCoV) Guidance for primary care Management of patients presenting to primary care Version 5.0, 2020.

4. Summary of infection prevention practices in dental settings. CDC(Centers for Disease Control and Prevention), 2016.

5. Cleaning and disinfection of environmental surfaces in the context of COVID-19, WHO, 15 May 2020.

6. Best Practices for Environmental Cleaning in Healthcare Facilities: in Resource-Limited Settings(ver1), 2019 